\title{
INCIDENCE AND OUTCOME OF MULTIDRUG RESISTANT AEROBIC GRAM-NEGATIVE BACTERIA CAUSING VARIOUS CLINICAL INFECTIONS
}

\author{
PURIMITLA USHARANI* \\ Department of Microbiology, Dr. Patnam Mahender Reddy Institute of Medical Sciences, Hyderabad, Telangana, India. \\ Email: purimitlausha2@gmail.com
}

Received: 04 September 2021, Revised and Accepted: 18 December 2021

\section{ABSTRACT}

Objective: The purpose of the present study was to isolate, characterize, and evaluate Gram-negative antibiotic bacteria isolated from different clinical samples.

Methods: The Clinical and Laboratory Standard Institute guidelines were used to isolate and identify microbial isolates on Muller-Hinton agar using standard bacteriological techniques and to monitor for antibiotic susceptibility by disc diffusion method.

Results: The study involved 129 clinical samples that were obtained from 70 males and 59 females. A maximum number of cases were recorded in the age group 51-60 (33\%) followed by 41-50 (16\%). The results showed that the common isolates were Escherichia coli 49 (37\%), Klebsiella spp. 37 (28\%), Pseudomonas aeruginosa 30 (23\%), and among 12\% microbial isolates, four isolates were Proteus species, seven isolates were Citrobacter species, and two isolates were Providencia species. The most of the isolates were multidrug resistant isolates. However, few isolates showed sensitivity to meropenem and imipenem and most of them were colistin sensitive. Out of 129 isolated microorganisms, 53 isolates were again screened for carbapenemase production through modified Hodge test. It was found that 50 strains were positive for carbapenemase producers ( $94 \%$ ) and three strains were negative for carbapenemase production (6\%). E. coli and P. aeruginosa followed by Klebsiella species showed carbapenemase production. Among the 50 strains that were positive for the development of carbapenemase, 47 strains were susceptible to colistin that was identified by the "E" strip method and three strains showed resistance to colistin.

Conclusion: The study allows clinicians to select the right antimicrobial agent that not only leads to improved treatment but also helps to avoid the emergence of drug resistance strains which are still sensitive.

Keywords: Gram-negative bacteria, Multidrug resistant bacteria, Modified Hodge test, Colistin.

(C) 2022 The Authors. Published by Innovare Academic Sciences Pvt Ltd. This is an open access article under the CC BY license (http://creativecommons.org/ licenses/by/4.0/) DOI: http://dx.doi.org/10.22159/ajpcr.2022v15i2.43436. Journal homepage: https://innovareacademics.in/journals/index.php/ajpcr

\section{INTRODUCTION}

The massive spread of multidrug-resistant (MDR) bacteria among humans, livestock, and environmental reservoirs has now created new unexpected epidemiological trends in health-care facilities for these bacteria. Overtime shifts have occurred in global infection epidemiology in patients, marked by a transition from predominant Gram-negative bacteria between the 1960 s and 1970 s to Gram-positive bacteria 10 years later and, beyond that, a fresh restitution of Gram-negative bacteria in several countries over the past 20 years. Enterobacteriaceae, primarily Klebsiella pneumoniae, Pseudomonas aeruginosa, Escherichia coli etc., resistant to different groups of antibiotics, including carbapenems, colistin, and polymyxins, have been increasingly involved as infecting pathogens and are responsible for both population and hospital-related infections and are involved in high morbidity and mortality rates across both sexes and ages. Such species are highly responsible for causing urinary tract infections, pneumonia, peritonitis, meningitis, sepsis, and infections associated with medical devices [1-10]. In general, carbapenem antibiotics such as imipenem, ertapenem, meropenem, and doripenem are used as the medication of choice for infections caused by extended spectrum beta-lactams (ESBL) manufacturers. Today, acquired resistance to beta-lactams is predominantly mediated by the ESBLs, AmpC-type cephalosporinases, and carbapenemases. From the literature survey, it was found that resistant microbial strains increase the worldwide development of $\beta$-lactamases, hydrolyzing all $\beta$-lactam antibiotics, including carbapenems. Veronica integron Metallo-betalactamase (MBL), Imp sort, KPC, and Oxacillinase-48 are the key forms of carbapenemase and MDR or pandrug-resistant and difficult to treat infections usually induced by CRE species. This leads to an increase in morbidity, mortality, and the cost of health care. Since the most CREs are resistant to many antimicrobial groups, colistin, polymyxin-B, aztreonam, tigecycline, fosfomycin, and rifampin are needed for additional antibiotic susceptibility testing [11-15]. Although colistin is used as the last line of medication of choice, nephrotoxicity, which was seen in half of the patients treated with high parenteral doses, but which appears to be reversible in most cases, is the key adverse effect of colistin. These resistant strains, however, are susceptible to colistin and very few studies have recorded the prevalence of resistant strains with colistin. The growing use of colistin, however, explains why acquired resistance to colistin can now be applied to the resistance trait of carbapenem in Enterobacteriaceae. Hence, there is a need for tests that enable rapid detection of carbapenem and polymyxin resistance in Enterobacteriaceae and that may contribute to its containment. Hence, the present study employs some rapid tests for the detection of carbapenem and colistin resistant strains of Enterobacteriaceae isolated from the various infectious patient samples for the disease management therapy and to prevent the dissemination of resistant genes among the GNB.

\section{METHODS}

It is a retrospective analysis. Different clinical samples obtained from patients with both inpatient (IP) and outpatient (OP) from tertiary care teaching hospital were the material for this research. Clinical specimens including pus, urine, blood, endotracheal aspirates, sputum, and ascitic fluid. Patient demographic variables were identified including age, sex, type of patient (IP or OP), and samples. Gram's staining was initially conducted to study the patient's demographic variables. 
Blood agar, chocolate agar, and MacConkey agar are inoculated in the specimens. With the exception of chocolate agar incubated with increased carbon dioxide, all other inoculated agar plates were aerobically incubated for $24 \mathrm{~h}$ at $35-37^{\circ} \mathrm{C}$.

For direct gram staining to make a presumptive diagnosis, the second swab was used. Identification of isolates was done using combination of colonial characteristics, gram staining characteristics, and conventional standard biochemical tests. BACT ALERT System (bioMerieux) was used to isolate and identify the bacterial isolates in blood samples. The culture of pathogens enables colonies of pure growth to be isolated for identification and antimicrobial susceptibility testing. The specimen is streaked on the culture plates (Blood agar and Mac Conkey agar) and incubated at $37^{\circ} \mathrm{C}$ for $24 \mathrm{~h}$. Urine samples were inoculated into cystine-lactose-electrolytedeficient agar. Following culture methods, biochemical tests are often required to identify pathogens using substrates and sugars to detect their enzymatic and fermentation reactions. The tests include carbohydrate fermentation tests with glucose, lactose, sucrose, xylose, mannitol, and maltose. The organisms were also tested for indole production, methyl red test, Voges-proskauer test, citrate utilization, urease test, oxidase test, catalase test, nitrate reduction test, triple sugar iron agar test, etc.

\section{Antibiotic susceptibility testing}

Disc diffusion method: Antibiotic susceptibility was checked by KirbyBauer's disc diffusion method. According to the Clinical and Laboratory Standard Institute (CLSI) guidelines, the process was carried out. Using a sterile pair of forceps, selected antibiotic discs were placed aseptically on the surface of the inoculated media after $5 \mathrm{~min}$. The MHA plates were incubated for $16-18 \mathrm{~h}$ at $37^{\circ} \mathrm{C}$. The antibiotic discs used in this study were Piperacillin (100 $\mu \mathrm{g})$, Amikacin $(30 \mu \mathrm{g})$, Gentamicin $(10 \mu \mathrm{g})$, Ceftazidime (30 $\mu \mathrm{g})$, Ciprofloxacin (5 $\mu \mathrm{g})$, Imipenem $(10 \mu \mathrm{g})$, Ampicillin/Sulbactum $(10 / 10 \mu \mathrm{g})$, Colistin E strips, Ampicillin (10 $\mu \mathrm{g})$, Amoxyclav $(20 / 10 \mu \mathrm{g})$, Cotrimoxazole (25 $\mu \mathrm{g})$, Cefepime $(30 \mu \mathrm{g})$, Cefuroxime (30 $\mu \mathrm{g})$, Ceftazidime/Clavulanic acid $(30 / 10 \mu \mathrm{g})$, Nitrofurantoin $(300 \mu \mathrm{g})$, and Tetracycline $(30 \mu \mathrm{g})$. The inhibition zone was measured according to the CLSI guidelines (CLSI Catalog, 2016) (Collee, 2006) [16].

\section{ESBL confirmation}

Bacterial suspensions have been calibrated to 0.5 McFarland turbidity and distributed uniformly on MHA, two plates per strain, in all directions. Ceftazidime $(30 \mu \mathrm{g})$ and ceftazidime/clavulanic acid $(30 / 10 \mu \mathrm{g})$ disks (Himedia Pvt. Ltd) were mounted on the petri dish and then incubated at $37^{\circ} \mathrm{C}$ for $16-18 \mathrm{~h}$. An increase in the zone diameter of $5 \mathrm{~mm}$ for either antimicrobial agent measured in combination with clavulanic acid was reported as ESBL-positive strains according to the CLSI criteria when tested alone [17].

\section{Identification of MBL producers by ethylenediaminetetraacetic} acid (EDTA) double synergy test

An overnight culture (0.5 McFarland opacity standards) of the test isolate was inoculated on an MH agar. A $10 \mu$ gimipenem disc and a sterile blank disc (Hi-media) were positioned $10 \mathrm{~mm}$ apart from edge to edge after drying. Another disc with imipenem was placed far as control. A 0.5 M EDTA (Himedia) solution volume of $10 \mu \mathrm{l}$ was added to the blank disc. The zone of inhibition around the imipenem disc expands toward the EDTA disc after overnight incubation compared to the other imipenem disc, placed on the far side, and was interpreted as a positive result [17].

\section{Identification of carbapenemase producing organisms by modified} Hodge test

The production of carbapenemase was established if the microbial isolate tested was capable of producing an enzyme and allowed the growth of the standard E. coli ATCC 25922 strain into the carbapenem disc. Based on the observation of clover leaf-like indentation, the findings were noted [1].

\section{Detection of colistin resistant organisms by E-test method}

A suspension of each test bacterial isolate was initially prepared and adjusted to 0.5 McFarland standards in the Mueller-Hinton broth. The suspensions on MHA plates have now been swabbed. When the agar surface was fully dry, a colistin E-strip was applied to each plate (concentration varying from $0.06-1.024 \mu \mathrm{g} / \mathrm{ml}$ and incubated for $16-$ $20 \mathrm{~h}$ at $35^{\circ} \mathrm{C}$. The results were recorded as MIC where growth inhibition intersected the E-strip. As the breakpoint for select as resistant isolates, a colistin concentration of about $4 \mu \mathrm{g} / \mathrm{ml}$ was used.

\section{Statistical analysis}

Data were statistically analyzed using SPPS software version 24.0. Frequency and percentages were calculated for categorical and ordinal variables. Chi-square test was carried out and $p \leq 0.05$ was considered statistically significant.

\section{RESULTS}

The study involved 129 clinical samples that were obtained from 70 males and 59 females. A maximum number of cases were recorded in the age group 51-60 (33\%) followed by $41-50(16 \%)$ (Table 1). A maximum number of samples were urine 51 (39\%), pus $28(21 \%)$, sputum $22(17 \%)$, blood $15(11 \%)$, and other samples $12 \%$ constitute six throat swabs, four corneal swabs, two CSF, and oneascitic fluid. The most of the microorganisms isolated were E. coli 49 (37\%), Klebsiella spp. 37 (28\%), P. aeruginosa 30 (23\%), and 12\% comprises four isolates of Proteus species, seven isolates of Citrobacter species, and two isolates of Providencia species. Table 2 showed that out of 49 isolates 15 E. coli strains were sensitive to amikacin and imipenem and majority are MDR isolates (Fig. 1). Out of four isolates of Proteus species, only one isolate showed sensitivity to imipenem and meropenem. Providencia species showed maximum sensitivity to amikacin. The isolated Klebsiella species and Citrobacter species and non-fermentative Gram-negative bacilli like P. aeruginosa (Table 3) also showed high resistance to maximum tested antibiotics except meropenem and imipenem. The 53 test isolates which showed resistance to imipenem by Kirby-Bauer disc diffusion method were now tested for the MBL production by EDTA combined disc method. The results showed that out of 53 bacterial isolates, 50 isolates showed MBL production (94\%) and 3 non-MBL producers (6\%). Maximum MBL production was seen in E. coli, Klebsiella species and $P$. aeruginosa. All these 53 isolates were again screened for carbapenemase production through modified Hodge test. It was found that 50 strains were positive for carbapenemase producers $(94 \%)$ and three strains were negative for carbapenemase production $(6 \%)$. The majority of the strains were E. coli and P. aeruginosa followed by Klebsiella species showed carbapenemase production. Among these 50 strains which were positive for carbapenemase production, 47 strains were sensitive to colistin which was detected by "E" strip method and three strains showed resistance to colistin (Fig. 2).

\section{DISCUSSION}

The rise of GNB in hospital acquired infections (HAI) in India over the past decade, with increasingly growing patterns. In the event of a failure to control the pathogen within the first 24-48 h, the risk of increased mortality among patients with HAI could be resistant to certain widely

Table 1: Distribution of clinical cases according to their age groups

\begin{tabular}{ll}
\hline Age groups & Frequency \\
\hline$<10$ & 3 \\
$11-20$ & 4 \\
$21-30$ & 16 \\
$31-40$ & 15 \\
$41-50$ & 21 \\
$51-60$ & 43 \\
$61-70$ & 14 \\
$71-80$ & 13 \\
Total & 129 \\
\hline
\end{tabular}


Table 2: Antibiogram of Gram-negative bacterial isolates

\begin{tabular}{|c|c|c|c|c|c|c|c|c|c|c|}
\hline \multirow[t]{2}{*}{ Antibiotics } & \multicolumn{2}{|l|}{$\begin{array}{l}\begin{array}{l}\text { E. coli } \\
(\mathrm{n}=49)\end{array} \\
\end{array}$} & \multicolumn{2}{|c|}{$\begin{array}{l}\text { Proteus species } \\
(\mathrm{n}=4)\end{array}$} & \multicolumn{2}{|c|}{$\begin{array}{l}\text { Providencia species } \\
(\mathrm{n}=2)\end{array}$} & \multicolumn{2}{|c|}{$\begin{array}{l}\text { Klebsiella species } \\
(\mathrm{n}=37)\end{array}$} & \multicolumn{2}{|c|}{$\begin{array}{l}\text { Citrobacter species } \\
(\mathrm{n}=7)\end{array}$} \\
\hline & $\begin{array}{l}\text { Sensitivity } \\
\text { (Number } \\
\text { and \%) }\end{array}$ & $\begin{array}{l}\text { Resistance } \\
\text { (Number } \\
\text { and \%) }\end{array}$ & $\begin{array}{l}\text { Sensitivity } \\
\text { (Number } \\
\text { and \%) }\end{array}$ & $\begin{array}{l}\text { Resistance } \\
\text { (Number } \\
\text { and \%) }\end{array}$ & $\begin{array}{l}\text { Sensitivity } \\
\text { (Number } \\
\text { and \%) }\end{array}$ & $\begin{array}{l}\text { Resistance } \\
\text { (Number } \\
\text { and \%) }\end{array}$ & $\begin{array}{l}\text { Sensitivity } \\
\text { (Number } \\
\text { and \%) }\end{array}$ & $\begin{array}{l}\text { Resistance } \\
\text { (Number } \\
\text { and \%) }\end{array}$ & $\begin{array}{l}\text { Sensitivity } \\
\text { (Number } \\
\text { and \%) }\end{array}$ & $\begin{array}{l}\text { Resistance } \\
\text { (Number } \\
\text { and \%) }\end{array}$ \\
\hline Ampicillin & $0(0)$ & $49(100)$ & $0(0)$ & $4(100)$ & $0(0)$ & $2(100)$ & $2(5.4)$ & 35 (94.6) & $1(14.2)$ & $6(85.8)$ \\
\hline Cefipime & $3(7)$ & $46(93)$ & $0(0)$ & $4(100)$ & $0(0)$ & $2(100)$ & $8(21.6)$ & $29(78.4)$ & $2(28.5)$ & $5(71.5)$ \\
\hline Ceftriaxone & $2(5)$ & 47 (95) & $0(0)$ & $4(100)$ & $0(0)$ & $2(100)$ & $3(8.1)$ & 34 (91.9) & $0(0)$ & 7 (100) \\
\hline Cefuroxime & $1(3)$ & $48(97)$ & $0(0)$ & $4(100)$ & $0(0)$ & $2(100)$ & $2(5.4)$ & 35 (94.6) & $0(0)$ & $7(100)$ \\
\hline Ciprofloxacin & $5(11)$ & $44(89)$ & $0(0)$ & $4(100)$ & $0(0)$ & $2(100)$ & $4(10.9)$ & 33 (89.1) & $1(14.2)$ & $6(85.8)$ \\
\hline Cotrimoxazole & $3(7)$ & $46(93)$ & $0(0)$ & $4(100)$ & $0(0)$ & $2(100)$ & $12(32.4)$ & $25(67.6)$ & $2(28.5)$ & $5(71.5)$ \\
\hline Amikacin & $15(31)$ & $34(69)$ & $0(0)$ & $4(100)$ & $2(100)$ & $0(0)$ & $20(54)$ & $17(46)$ & $4(57)$ & $3(43)$ \\
\hline Imipenem & $15(31)$ & $34(69)$ & $1(25)$ & $3(75)$ & $1(50)$ & $1(50)$ & $30(81)$ & 7 (19) & $6(85.7)$ & $1(14.3)$ \\
\hline Gentamycin & $12(25)$ & $37(75)$ & $0(0)$ & $4(100)$ & $1(50)$ & $1(50)$ & $14(37.9)$ & $23(62.1)$ & $5(71.5)$ & $2(28.5)$ \\
\hline Ceftazidime & $0(0)$ & $49(100)$ & $0(0)$ & $4(100)$ & $0(0)$ & $2(100)$ & $5(13.5)$ & 32 (86.5) & $0(0)$ & $7(100)$ \\
\hline $\begin{array}{l}\text { Ceftazidime/ } \\
\text { clavulanic acid }\end{array}$ & $1(3)$ & 48 (97) & $0(0)$ & $4(100)$ & $1(50)$ & $1(50)$ & 7 (19) & $30(81)$ & $0(0)$ & 7 (100) \\
\hline $\begin{array}{l}\text { Ampicillin/ } \\
\text { sulbactam }\end{array}$ & $1(3)$ & $48(97)$ & $1(25)$ & $3(75)$ & $0(0)$ & $2(100)$ & $5(13.5)$ & $32(86.5)$ & $2(28.55)$ & $5(71.5)$ \\
\hline Tetracycline & $3(7)$ & $46(93)$ & $0(0)$ & $4(100)$ & $0(0)$ & $2(100)$ & $8(21.6)$ & $29(78.4)$ & $1(14.2)$ & $6(85.8)$ \\
\hline Ertapenem & $10(21)$ & $39(79)$ & $0(0)$ & $4(100)$ & $1(50)$ & $1(50)$ & $9(24.3)$ & 28 (75.7) & $3(42.8)$ & $4(57.2)$ \\
\hline Chloramphenicol & $4(29)$ & $35(71)$ & $0(0)$ & $4(100)$ & $0(0)$ & $2(100)$ & 7 (19) & $30(81)$ & $1(14.2)$ & $6(85.8)$ \\
\hline Meropenem & $13(27)$ & $36(73)$ & $1(25)$ & $3(75)$ & $1(50)$ & $1(50)$ & $32(86.5)$ & $5(13.5)$ & $7(100)$ & $0(0)$ \\
\hline $\mathrm{p}<0.01$ & & & $<0.01 \mathrm{HS}$ & & $<0.01 \mathrm{HS}$ & & $<0.01 \mathrm{HS}$ & & $<0.01 \mathrm{HS}$ & \\
\hline
\end{tabular}

HS: Highly significant, $P$ value: Probability value. E. coli: Escherichia coli

Table 3: Antibiogram of non-fermentative Gram-negative bacteria Pseudomonas species

\begin{tabular}{lll}
\hline Antibiotics & $\begin{array}{l}\text { Sensitivity } \\
\text { (Number and \%) }\end{array}$ & $\begin{array}{l}\text { Resistance } \\
\text { (Number and \%) }\end{array}$ \\
\hline (n=30) & $6(20)$ & $24(80)$ \\
Cefipime & $14(46)$ & $16(54)$ \\
Amikacin & $4(13)$ & $26(87)$ \\
Ciprofloxacin & $2(7)$ & $28(93)$ \\
Cotrimoxazole & $7(24)$ & $23(76)$ \\
Ceftazidime/clavulanic acid & $20(66)$ \\
Gentamycin & $10(34)$ & $28(93)$ \\
Ceftazidime & $2(7)$ & $28(93)$ \\
Ampicillin/sulbactam & $2(7)$ & $7(24)$ \\
Imipenem & $23(76)$ & $25(83)$ \\
Piperacillin & $5(17)$ & \\
p-value & $<0.01 \mathrm{HS}$ &
\end{tabular}

HS: Highly significant

used groups of antibiotics by encoding and expressing some drug resistant genes and therefore being multidrug resistant and restricting the options for the treatment. The results of the present study were in accordance to Shindo et al. [18] isolated many MDR isolates in their study and concluded that main risk factors for MDR pathogens were identified: Prior hospitalization, immunosuppression, previous antibiotic use, use of gastric acid-suppressive agents, tube feeding, and non-ambulatory status.

In general, the last line of defense against many pathogenic species immune to other antimicrobial agents is carbapenems. However, there is a rise in the worldwide development of resistant microbial strains of beta-lactamase enzymes, thereby hydrolyzing all $\beta$-lactam antibiotics along with carbapenems. However, colistin is one of the older medications, but now has become a common alternative for clinicians facing few choices in the treatment of Gram-negative MDR bacteria. The growing global trend in carbapenemase resistance is a major concern as it reduces the variety of therapeutic options that require clinicians to use costly agents such as colistin that are associated with severe toxicity. In the Tertiary Care Hospital, reports of infections caused by MDR non-fermentative Gram-negative bacteria and Enterobacteriaceae are increasingly reported. For the identification of MDR isolates, different

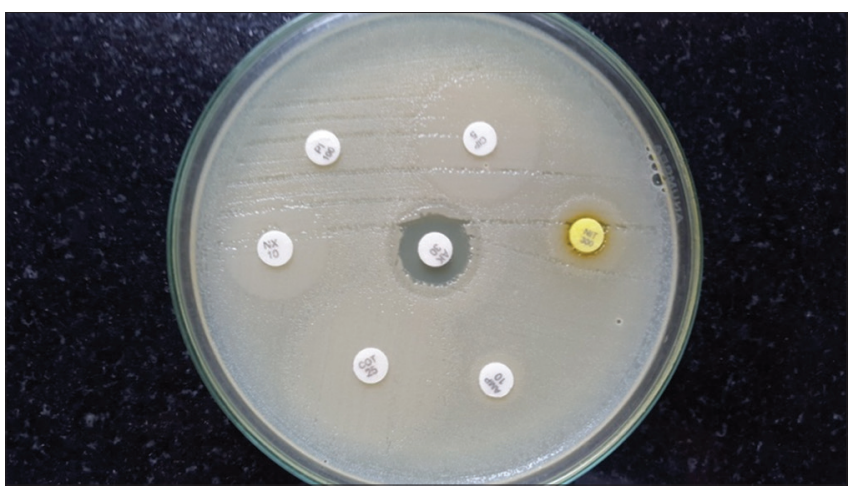

Fig. 1: Antibiotic susceptibility pattern of isolates by Kirby-Bauer method

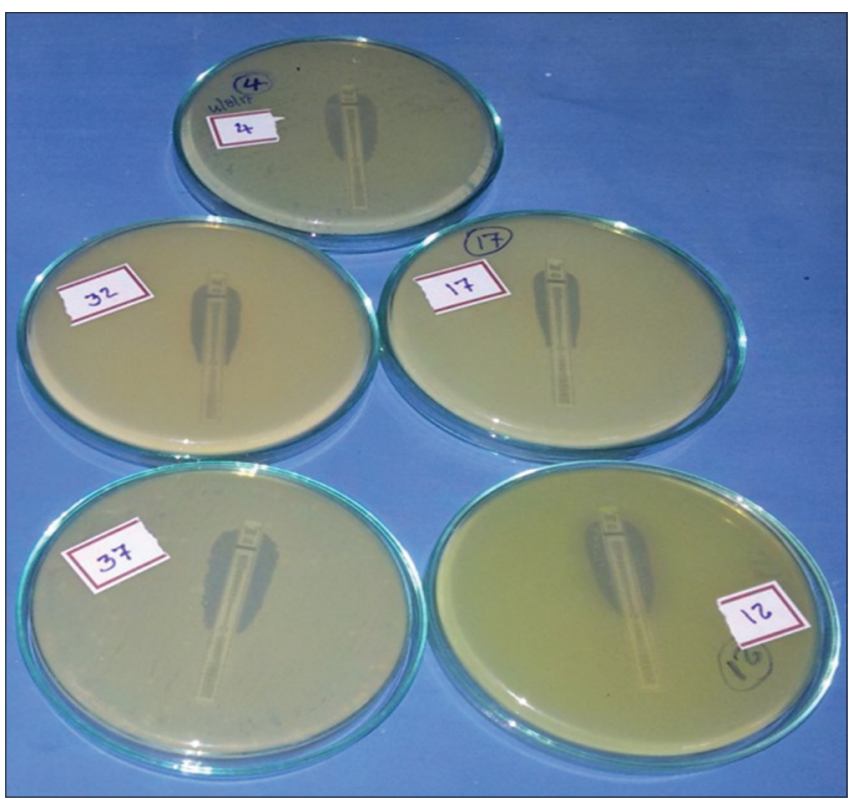

Fig. 2: Detection of colistin sensitivity by "E" strip method 
phenotypic methods and molecular methods were used. Most studies documented dismal outcomes among patients with enterobacteria immune to carbapenem ranging from 40 to $70 \%$, which are in near agreement with the present research. These bad results are due to patient comorbidities, disease severity, and treatment with inadequate empiric antibiotics before the laboratory detects carbapenem resistance. According to the Galani et al. [19], MHT is $98 \%$ sensitive method keeping polymerase chain reaction as the gold standard assay method. The test isolates of the present study showed high sensitivity to antibiotics like colistin (100\%) similar to the reports of Hirsch et al. [20], amikacin (54.2\%) followed by gentamycin (38.9\%) coincides that the findings of Anupurba et al. [21] reported least maximum sensitivity to amikacin and gentamycin $45.45 \%$. The majority of the studies had report dismal outcomes among patients with carbapenem resistant enterobacteria ranging from $40 \%$ to $70 \%$ [22] which is in close agreement to the present study. These poor outcomes are due to patient comorbidities, severity of illness, and treatment with ineffective empiric antibiotics before carbapenem resistance is identified by the laboratory.

\section{CONCLUSION}

The present research isolated very high isolates from different clinical samples of drug resistant species. The early identification of such drug-resistant microorganisms can aid at the beginning of prompt antimicrobial therapy and thus avoid the production and dissemination in the hospital as well as in the community of these multidrug resistance strains. The study helps clinicians select the right antimicrobial agent that not only leads to better treatment, but also helps to avoid the development of drug resistant strains that are still susceptible.

\section{AUTHORS' CONTRIBUTION}

The main author of the study PUR had performed the work, wrote the first draft of the manuscript, collected the literature, and performed the statistical part of the work.

\section{CONFLICT OF INTEREST}

The authors declared no conflict of interest.

\section{SOURCE OF FUNDING}

The study was not supported by any grants and funds.

\section{ETHICS CLEARANCE}

A proposal regarding the study's aims and objectives was submitted to the Institutional Ethics Committee and Dr. Patnam Mahender Reddy Institute of Medical Sciences (PMRIMS) and permission was obtained from the Institutional Ethics Committee regarding data collection from the university students.

\section{REFERENCES}

1. Amjad A, Mirza IA, Abbasi SA, Rarwa U, Malik N, Zia F. Modified hodge test for detection of carbapenemase production. Iran J Microbiol 2011;3:189-93.

2. Amudhan SM, Sekar U, Arunagiri K, Sekar B. OXA Beta-lactamase mediated carbapenem resistance in Acinetobacter baumannii. Ind $\mathrm{J}$ Med Microbiol 2011;29:243-5.

3. Anderson DJ, Engemann JJ, Harrell LJ, Carmeli Y, Reller LB, Kaye KS. Predictors of mortality in patients with bloodstream infection due to ceftazidime-resistant Klebsiella pneumoniae. Antimicrob Agents
Chemother 2006;50:1715-20.

4. Antoniadou A, Kontopidou F, Poulakou G, Koratzanis E, Galani I, Papadomichelakis E, et al. Colistin-resistant isolates of Klebsiella pneumoniae emerging in intensive care unit patients: first report of a multiclonal cluster. J Antimicrob Chemother 2007;59:786-90.

5. Sarkar A, Sen MR, Nath G, Sharma BM, Gulati AK, Mohapatra TM. Prevalence of methicillin resistant Staphylococcus aureus in a tertiary care referral hospital in Eastern Uttar Pradesh. Indian J Med Microbiol 2003;21:49-51.

6. Bartolini A, Frasson I, AntoniettaCavallaro, Richter SN, Giorgio P. Comparison of phenotypic methods for the detection of carbapenem non-susceptible Enterobacteriaceae. Gut Pathog 2014;6:1-7.

7. Basak S, Attal RO, Mallick SK, Bose S. Mettalobetalactamase producing Pseudomonas aeruginosa: An emerging threat to clinicians. J Clin Diagn Res 2010;4:2691-6.

8. Ben-David D, Maor Y, Keller N, Regev-Yochay G, Tal I, Shachar D, et al. Potential role of active surveillance in the control of a hospitalwide outbreak of carbapenem-resistant Klebsiella pneumonia infection. Infect Cont Hosp Epid 2010;31:620-6.

9. Bisson G, Fishman NO, Patel JB, Edelstein PH, Lautenbach E. Extended-spectrum beta-lactamase-producing Escherichia coli and Klebsiella species: Risk factors for colonization and impact of antimicrobial formulary interventions on colonization prevalence. Infect Control Hosp Epidemiol 2002;23:254-60.

10. Bush K. New beta-lactamases in gram-negative bacteria: Diversity and impact on the selection of antimicrobial therapy. Clin Infect Dis 2001;32:1085-9.

11. Lin MF, Huang ML, Lai SH. Risk factors in the acquisition of extendedspectrum beta-lactamase Klebsiella pneumoniae: A case-control study in a district teaching hospital in Taiwan. J Hosp Infect 2003;53:39-45.

12. Medeiros AA. Evolution and dissemination of beta-lactamases accelerated by generations of beta-lactam antibiotics. Clin Infect Dis 1997;24 Suppl 1:S19-45.

13. Mendiratta DK, Deotale V, Narang P, Metallobetalactamases producing of $P$. aeruginosa in hospital from rural area. Indian $\mathrm{J}$ Med Res 2005;121:701-3.

14. Nordmann P. Carbapenamase producing Enterobacteriaceae; overview of a major public health challenge. Med Mal Infect 2014;44:51-6.

15. Nordmann P, Poirel L, Walsh TR, Livermore DM. The emerging NDM carbapenemases. Trends Microbiol 2011;19:588-95.

16. Collee JG, Fraser AG, Marmion BP, Simmons A. Mackie and McCartney Practical Medical Microbiology. $14^{\text {th }}$ ed. New Delhi: Churchill Livingstone; 2006.

17. Khatoon R, Khan SA, Jahan N. Antibiotic resistance pattern among aerobic bacterial isolates from osteomyelitis cases attending a tertiary care hospital of North India with special reference to ESBL, AmpC, MBL and MRSA production. Int J Res Med Sci 2017;5:482-90.

18. Shindo Y, Ito R, Kobayashi D, Ando M, Ichikawa M, Shiraki A, et al. Risk factors for drug-resistant pathogens in community-acquired and healthcare-associated pneumonia. Am J Respir Crit Care Med 2013;188:985-95.

19. Galani I, Rekatsina DP, Hatzaki D, Plachouras D, Souli M, Giamarellou H. Evaluation of different laboratory tests for the detection of metallo- $\beta$-lactamase production in Enterobacteriaceae. J Antimicrob Chemother 2008;61:548-53.

20. Hirsch EB, Guo B, Chang KT, Cao H, Ledesma KR, Singh M, et al. Assessment of antimicrobial combinations for Klebsiella pneumoniae carbapenemase-producing K. pneumoniae. J Infect Dis 2013;207:786-93.

21. Anupurba S, Sen MR, Nath G, Sharma BM, Gulati AK, Mohapatra TM. Prevalence of methicillin resistant Staphylococcus aureus in a tertiary referral hospital in Eastern Uttar Pradesh. Indian J Med Microbiol 2003;21:49-51.

22. Satlin M, Kubin CJ, Blumenthal JS, Cohen AB, Furuya EY, Wilson SJ, et al. Comparative effectiveness of aminoglycosides, polymyxin $\mathrm{B}$, and tigecycline for clearance of carbapenem-resistant Klebsiella pneumonia from urine. Antimicrob Agents Chemother 2011;55:5893-9. 